\title{
An assessment of teleworking as a practice for travel demand management
}

\author{
G. D. Lyons, BEng, PhD
}

Proc. Instn Civ

Engrs Transp.,

1998, 129, Nov.,

$195-200$

Paper 11692

Written discussion

closes 15 May

1999

- Provision of additional highway capacity is no longer an acceptable solution to continuing traffic growth. Travel demand management has therefore become an increasingly important alternative solution. This paper considers how, and to what extent, teleworking can influence travel demand. Key issues are considered with reference to existing research literature and a recent UK teleworking trial.

Keywords: information technology; reviews; transport management

\section{Introduction}

Journeys are seldom made for their own sake. Personal trips are made to reach centres of activity such as schools, offices, shopping centres and leisure parks. Hence travel demand is derived from the need or desire to participate in activities. The location of an activity centre can influence the distance, duration, mode and route of associated trips. Central Government's Planning Policy Guidance Notes PPG $13^{1}$ and $\mathrm{PPG}^{2}$ seek to achieve more efficient tripmaking associated with newly developed activity centres by reducing the length and number of trips by car and locating new development to make best use of available or proposed public transport services. However, such planning guidance can do little to change the existing land-use patterns and the associated patterns of travel demand.

2. The rapid advances in computer technology and telecommunications present an alternative opportunity to change the location of activities in which people participate. Many activities, ranging from business meetings to selection of groceries in a supermarket, are entirely or largely comprised of information exchange. With the telephone, fax and now the Internet with its e-mail and World Wide Web facilities, telecommunications allow information to be exchanged in a variety of ways without the need for physical travel. In the course of attempting to formalize and promote the use of telecommunications to substitute for actual physical trips, the term teleservices has emerged. Teleservices are activities in which the individual participates remotely. Those that are practised most, and therefore have the potential to achieve the highest reduction in travel demand, are of greatest interest to transport planners. Of all the teleserviceswhich include teleshopping, ${ }^{3}$ telebanking and teleconferencing ${ }^{4}$ - teleworking has been the most widely considered by transport practitioners. Teleworking typically results in the removal of commuting from the peak periods. As a consequence it offers the potential to achieve reductions in peak period congestion and pollution.

3 . It is certainly tempting to consider teleworking as a panacea for problems associated with modern lifestyles, including travel. As a travel demand option it has some distinct attributes of appeal to policy-makers: ${ }^{5}$ its implementation involves no lengthy lead times; there is no public resistance to its practice; it is already technologically feasible and relatively inexpensive to implement; and it expands, rather than restricts, personal choice in contrast to measures such as congestion-pricing and carsharing.

4. This paper considers the key issues associated with teleworking and its travel demand impacts. It is based on a short review study conducted by the author for London Transport Planning ${ }^{6}$ and on a UK teleworking trial for which the author coordinated and jointly conducted the monitoring and evaluation. $^{7}$

5. The implications of teleworking for transport have been the focus of research for more than ten years with notable work in the United States by Mokhtarian ${ }^{5,8-12}$ and others. To fully appreciate the travel demand impacts of teleworking, it is necessary to also understand the issues that dictate how, and to what extent, teleworking is practised. This paper therefore follows the process of

(a) defining what teleworking means

(b) establishing, and understanding factors which influence, the current and future levels of adoption

(c) identifying travel demand changes that might take place as a result of teleworking.

\section{ENTRANCE teleworking trial}

6. Hampshire County Council was the UK lead partner in the European transport project 'ENTRANCE' (energy savings in transport through innovations in the cities of Europe).

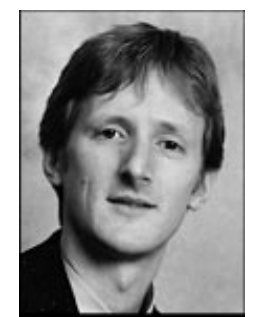

G. D. Lyons, Transportation Research Group, Department of Civil and Environmental Engineering, University of Southampton 
One component of the project was a UK teleworking trial in which 24 individuals from four organizations were given the opportunity to telework for the first time. Before and after the opportunity to telework, a series of mailback and interview questionnaires and sevenday travel diaries were used to collect information concerning the circumstances, opinions, aspirations, behaviour and travel of the trial participants. A parallel questionnaire survey of established teleworkers (who were matched to the trial teleworkers in terms of being company employees teleworking at home on a part-time basis) was also conducted to compare results from the trial. This is believed to be the first study of its kind in the UK.

\section{Defining teleworking}

7. Teleworking has often been typified by the scenario in which an individual lives and works in an idyllic location remote from civilization; an existence made possible with the aid of new computer and communications technologies. Teleworking does not, however, always represent a full-time practice and although the use of computers, fax-modems, etc. is increasingly common, they are not precursors for teleworking.

8. Differing objectives and interpretations have given rise to a large number of definitions of teleworking and of what constitutes a teleworker. ${ }^{13}$ Table 1 illustrates the key concepts that shape most, if not all, of the definitions. However, an important distinction of terms identifies a form of teleworking that has been the focus of most transport-related research. Nilles ${ }^{14}$ describes teleworking as the alternative to work-related travel. A subset of teleworking is telecommuting, that is, the alternative to daily commuting. Two forms of telecommuting are homeworking and working at a telecottage. Homeworking, as the name suggests, is when an individual's home is used as the workplace for all or part of the working week. A telecottage is a local workcentre that has facilities to enable individuals to conduct their business without the need to commute longer distances to their normal workplace. The former represents the preferred practice in travel demand terms since commuting is removed. In the latter, only the length of the commuting is reduced. This may have implications for the mode of travel used for commuting. Commuting formerly done by car may instead be done by cycling or walking. Alternatively, commuting formerly done by train may instead be done by car, perhaps in the absence of a convenient local public transport alternative.

9. Homeworking is often seen as unappealing because it introduces social isolation and reduces an employee's presence in the office and interaction with colleagues. However, rather
Table 1. Concepts used to establish definitions of teleworking

\begin{tabular}{|c|c|}
\hline Concept & Comment \\
\hline Technology & $\begin{array}{l}\text { Computing and telecommunications may be deemed an } \\
\text { essential enabler or treated as a non-essential } \\
\text { facilitator }\end{array}$ \\
\hline Work location & $\begin{array}{l}\text { Teleworking in its broadest sense can take place in the } \\
\text { office, at home, in a hotel room, in a remote office, in a } \\
\text { train or in a car-i.e. whenever the location is remote } \\
\text { from central facilities and/or when remote } \\
\text { communication is taking place }\end{array}$ \\
\hline Employment status & $\begin{array}{l}\text { Employees will typically work in a conventional office } \\
\text { and need employer consent to telework while self- } \\
\text { employed workers are often home-based and as such } \\
\text { are already remote from a conventional workplace }\end{array}$ \\
\hline Time of day & $\begin{array}{l}\text { Teleworking may be interpreted as a substitute for } \\
\text { work done during normal office hours or may } \\
\text { constitute overtime or extra work done in the evenings } \\
\text { or at weekends }\end{array}$ \\
\hline Frequency & $\begin{array}{l}\text { Teleworking may be a full-time working practice, a } \\
\text { regular part-time practice or an infrequent practice }\end{array}$ \\
\hline
\end{tabular}

than causing the demise of homeworking, this has led to homeworking being practised on a part-time basis. Teleworkers in the ENTRANCE trial worked at home for an average of 1.2 days per week. Similar frequencies have been observed in other studies. ${ }^{8,15}$ As a part-time working practice, the benefits of homeworking can be enjoyed. The four most frequently cited benefits in the ENTRANCE trial were

(a) the opportunity to better address family and personal issues

(b) the opportunity to work without interruption or distraction

(c) increased flexibility

(d) commuting-related benefits (time and cost savings and reduced stress).

10. The use of telecommunications has been considered as 'an essential enabler for the work to be done remotely'. ${ }^{16}$ An arguably more appropriate opinion ${ }^{17}$ is that telecommuting 'reduces dependency on transportation by increasing dependency on information technologies'. Homeworking can be practised with little more than a pen and paper. Indeed, the provision of communications links between the home and office conflicts with the benefit of having no interruptions when homeworking. However, as telecommunications and computing continue to become more widely available at reduced prices, telecommunications can certainly act as a facilitator for homeworking, making it more convenient for a greater number of people.

\section{Adoption levels}

11. The value of telecommuting as a form of travel demand management depends upon the 
extent to which it is practised. However, estimates of current levels of telecommuting are compounded by the differing definitions associated with limited sources of available statistics. Predictions of future levels have been 'primarily based on hypothetical scenarios embodying a range of assumptions about future adoption'. ${ }^{5}$ Consequently, there are a number of conflicting estimates and predictions. However, further to a recent report for the UK Government, ${ }^{18}$ additional questions have now been added to its Labour Force Survey. The spring 1997 survey $^{19}$ estimates that there are 987000 homeworkers in Great Britain, representing 4\% of total employment. The survey's definition of a homeworker was an individual who worked at least one full day at home in the reference week. The survey noted that one-third of employed teleworkers are in the service industries of banking, finance and insurance.

12. This raises the issue of what percentage of total employment has the potential to adopt telecommuting. Manufacturing industry in particular is unlikely to respond to the same extent as the service industries. Thirty-four per cent of major employers approached for possible participation in the ENTRANCE trial considered that their organization was not suitable for teleworking. The extent to which such organizations were incompatible with teleworking is unclear. From reasons given for non-participation it appears that in some cases incompat ibility is not absolute and a more adaptive and flexible approach to new working practices such as teleworking could enable the new working practices to be used. Nonetheless, the penetration of teleworking into the workforce will be limited. It has been estimated ${ }^{9}$ that $40 \%$ of US workers are potentially telecommuters.

13. The difficulty in obtaining accurate estimates of the extent of homeworking is also compounded by the issue of unofficial homeworkers. These are individuals who either do not wish to formalize their homeworking or are unaware that they are practising telecommuting. Sixty-two per cent of the ENTRANCE trial participants had worked at home for at least a week during the year prior to joining the trial.

14. The magnitude of travel demand impacts, at an aggregate level, is a product of the number of individuals who are telecommuters and the frequency with which they telecommute. Hence, using figures quoted earlier, if $4 \%$ of the workforce are homeworkers but they only work at home for 1.2 days per week on average, then less than $1 \%$ of the workforce, on average, are working from home on a given day.

15. Given that the travel demand benefits of existing telecommuting have already been realized and absorbed by continued traffic growth, it is the potential to increase future adoption levels that must be of importance to policy- makers. Early forecasts assumed adoption levels would be driven by developments and availability of information technology (IT). Successive forecasts have become more moderated with a realization that human behaviour is the primary driver ${ }^{20}$ and that the spread of telework was going to be more evolutionary than revolutionary'. ${ }^{21}$ One of the most important obstacles to adoption of telecommuting in 1985 was the high IT cost. Nine years later this had dropped in importance to be replaced by the difficulty in managing from a distance and inadequate knowledge of what telework really is. ${ }^{22}$ Awareness and an informed understanding of what telecommuting is and the benefits and disbenefits in terms of lifestyle and working practice that it can offer, must be key factors in promoting its adoption. Prior to teleworking, only $15 \%$ of ENTRANCE trial participants believed there to be no disbenefits from homeworking. Having experienced homeworking, this figure doubled to over $30 \%$ and all but one of the participants wished to continue homeworking once the trial ended. Education and awareness for both employers and employees must be encouraged.

\section{Travel demand impacts}

16. An optimistic scenario for the UK is that greater use of telecommunications and teleservices could cut projected growth in congestion ${ }^{23}$ by about $70 \% .{ }^{24}$ Contrasting views, however, demonstrate the lack of consensus. Mokhtarian ${ }^{10}$ now believes that teleservices will not achieve sizeable reductions in travel and that transportation and telecommunications will act largely as complements to each other and not as substitutes. The Institution of Civil Engineers is also cautious about the scale of travel demand impacts derived from teleworking. ${ }^{25}$ It notes that non-work journeys concerning leisure, holidays or visiting friends account for two-thirds of personal travel and an even greater proportion of the projected growth in travel demand. Such viewpoints draw upon issues concerning both adoption levels and travel demand impacts.

17. The principal impact of telecommuting in travel demand terms is the removal, or in the case of telecottages, reduction in length, of commuting. However, there are a number of potential secondary impacts that may offset this primary benefit. The need to recognize and understand these impacts has given rise to a number of detailed transport-related studies such as the ENTRANCE trial. Table 2 compares some key figures for the trial sample with corresponding national figures.

18. It is widely recognized that early adopters of telecommuting tend to have longer commuting distances. ${ }^{11,16,28}$

"If telecommuting is attractive primarily to long- 
distance commuters, then the ultimate adoption of telecommuting (and hence, its transportation benefits) will be more narrowly restricted than anticipated." 11

The average commuting distance and journey time from home in the ENTRANCE trial are substantially higher than the national averages (as shown in Table 2).

19. However, reducing the number of vehicle miles travelled is only one benefit of removing commuting travel. Vehicle emissions are also reduced and such a benefit is not solely dependent on an individual's commuting distance.

"A typical 5 mile trip generates 61 per cent of the hydrocarbon emissions of a typical 20 mile trip, because a high proportion of the emissions occur during the cold start, the first few minutes that the engine is running.,"12

Most commuting, regardless of length, either begins or ends in urban centres where congestion is most acute. Therefore, removal of any commuting, regardless of length, should help to ease congestion.

20. Short-term benefits achieved from many transport policies or schemes are potentially offset by latent demand, that is, the use of roads that manifests only at times when free-flowing capacity is available. ${ }^{29}$ This is recognized as one potential secondary impact of telecommuting. ${ }^{28-31}$ It has been suggested ${ }^{30}$ (in the US) that nearly half the benefits of removal of commuting could be offset by latent demand and increased urban sprawl.

21. If a telecommuter travels to work by car (only one of the ENTRANCE telecommuters used public transport) then on telecommuting days, the car becomes available to other household members to use for either commuting or non-commuting travel. Such use would have a negative impact for travel demand. However, encouragingly, there appears to be no evidence from studies to date ${ }^{11}$ that such use takes place. Indeed, two studies cited by Mokhtarian et al. ${ }^{11}$ that specifically considered this issue, observed a small reduction in the number of trips made by other household members. It was suggested that this may have been due to factors such as underreporting of trips in the studies and a heightened awareness of the need to reduce travel as a result of participating in such a study. In the ENTRANCE trial the absence of an increase in non-commuting travel was largely explained by the socio-economic status of telecommuting households in the studies considered. Two-thirds of the ENTRANCE sample classed themselves as senior to middle management and the median bracket of teleworker gross annual salary for the sample was $£ 30000-£ 35$ 000. Car ownership levels in the sample households were high, even when compared to national average figures for highest
Table 2. ENTRANCE trial sample averages compared with national averages

\begin{tabular}{l|c|c}
\hline Description & ENTRANCE & Great Britain \\
\hline $\begin{array}{l}\text { Household car ownership (assumes 'three or more } \\
\text { cars' households own three cars) }\end{array}$ & $1 \cdot 83$ & $0 \cdot 97^{26}$ \\
$\left(1 \cdot 44^{*}\right)^{27}$ \\
Commute distance: miles & $23 \cdot 4$ & $7 \cdot 8^{27}$ \\
Commute time: min & 36 & $24^{27}$ \\
\hline
\end{tabular}

*National average for highest quintile income households.

quintile income households (see Table 2). Consequently, most household members eligible to drive had their own cars. It should be noted that the trial sample was self-selected and while not typical of the population at large, is likely to be more typical of early adopters of teleworking or those most suited to teleworking. Non-commuting travel may, however, manifest itself if telecommuting becomes more widespread and includes households with lower car ownership levels.

22. An intriguing impact is that of part-day telecommuting. It may be argued that telecommuting is most suited to individuals who are self-disciplined, motivated and with most demands on their time and therefore least likely to secure whole days away from the office. Seventy per cent of the ENTRANCE trial participants had sometimes homeworked partdays. Such a form of telecommuting does not remove the journeys to and from work, unless business-related trips are made that originate from the home on such days. This was sometimes the case in the ENTRANCE trial. However, it must be noted that commuting is still removed from one or both of the peak periods. In this context part-day telecommuting achieves a form of peak spreading. Additionally, individuals seek to avoid part-day telecommuting where possible because of the obvious loss of travel benefits.

23. The interaction between land-use and transport was noted at the beginning of this paper. Changes in land-use can result from telecommuting, impacting in turn on travel demand. In particular, telecommuting has been considered as an influential factor in residential relocation. ${ }^{5,11,14,25}$ Telecommuting can serve to offset an increased commuting distance resulting from the choice to live further away from the normal place of work, perhaps in a more desirable rural location. There is limited evidence to assess this impact of telecommuting. Land-use changes take place over much longer time periods than those considered by teleworking trials. However, when asked, $26 \%$ of ENTRANCE trial participants considered telecommuting would influence any future housemove decision. Two established telecommuters included in the retrospective study had already been influenced as shown in Table 3 . 
24. The impacts of telecommuting, and indeed teleservices in general, on public transport are, as yet, largely indeterminate. However, there is some speculation that such impacts may be adverse. ${ }^{28,32}$ Latent demand resulting from a reduction in car-based commuting may result in some mode shift from public to private transport. If telecommuting replaces commuting by public transport, this will also result in reduced patronage. The potential decentralization effect of telecommuting alluded to previously, encourages spatial distributions of households and associated trips that are difficult to serve by public transport. Collectively these impacts, if substantial, could threaten the economic provision of public transport.

\section{Concluding remarks}

25. The amount of research already undertaken relating to telecommuting and travel is often overlooked. An appreciation of many of the relevant issues is now established although the scales of impact and longer-term consequences are poorly understood. Conflicting views remain concerning the extent to which telecommuting can be expected to contribute to travel demand. This may be the consequence, in part, of interpreting findings from different countries and regions. It may also be a consequence of attempting to interpret findings from detailed studies with small sample sizes and attempting to scale up the findings for the population at large. A definite need exists for further research, and research that is specific to the UK. At a European level, over 60 projects relate to telework, ${ }^{33}$ although nearly all of these concern themselves with technological or social issues rather than travel demand.

26. Telecommuting does deliver benefits but it should only be considered as part of the integrated transport solution that Central Government is now looking towards as a means to mitigate congestion and pollution. The UK Government has stated in its Transport White Paper $^{34}$ that it will

"focus efforts on communicating best practice and encouraging local authorities to support teleworking ... where this will substitute for high mileage car travel".

27. Any benefits derived from existing telecommuting have gone largely unnoticed in the face of rising traffic levels. Influencing future adoption levels must, therefore, be the key to telecommuting's transport success. Telecommuting represents a radical change to longestablished working practices. It is not surprising, therefore, that a natural resistance to change acts as the main barrier to higher levels of uptake. The ENTRANCE trial demonstrated that first-hand experience of telecommuting can help to dispel misconceptions. Any
Table 3. Residential location of some established teleworkers has been influenced by teleworking

\begin{tabular}{l|c}
\hline Response & $\begin{array}{c}\text { Homeworking } \\
\text { frequency of } \\
\text { respondent: } \\
\text { days/week }\end{array}$ \\
\hline $\begin{array}{l}\text { 'I do live } 100 \text { miles from the office-I couldn't manage that if } \\
\text { I wasn't teleworking' } \\
\text { 'Have already moved to a more desirable area further away } \\
\text { from work' }\end{array}$ & 3 \\
\hline
\end{tabular}

initiatives to raise awareness and understanding of telecommuting and the benefits it can offer are to be welcomed.

\section{References}

1. Department of the Environment and Department of Transport. Planning Policy Guidance 13: Transport. HMSO, London, 1994.

2. Department of the Environment. Planning Policy Guidance 6: Town Centres and Retail Developments. HMSO, London, 1996.

3. Salomon I. and Koppelman F. A framework for studying teleshopping versus store shopping. Transportation Research, 1988, 22A, No. 4, 247 255.

4. Bennison D. J. Transport/telecommunication interactions: empirical evidence from a videoconferencing field trial in the United Kingdom. Transportation Research, 1988, 22a, No. 4, 291300.

5. Mokhtarian P. L. Telecommuting and travel: state of practice, state of the art. Transportation, 1991, 18, No. 4, 319-342.

6. Lyons G. D. A Review of Teleworking and the Implications for Transport. Report to London Transport Planning, May 1996.

7. Lyons G. D., Hickford A. J. and Smith J. C. The potential impacts of teleworking on travel: results from a longitudinal UK case study. Proceedings of the 8th IATBR Conference, Telecommunications-Travel Interactions, Austin, Texas, 21-25 September 1997.

8. Lund J. and Mokhtarian P. Telecommuting and residential location: theory and implications for commuter travel in the monocentric metropolis. Transportation Research Record 1463, 1994, 1014.

9. Handy S. and Mokhtarian P. L. Forecasting telecommuting: An exploration of methodologies and research needs. Transportation, 1996, 23, 163-190.

10. Mokhtarian P. L. Now that travel can be virtual, will congestion virtually disappear? Scientific American, 1997, October.

11. Mokhtarian P. L., Handy S. L. and Salomon I. Methodological issues in the estimation of the travel, energy, and air quality impacts of telecommuting. Transportation Research, 1995, 29A, No. 4, 283-302.

12. Mokhtarian P. L. Defining telecommuting. Transportation Research Record 1305, 1991, 273281. 
13. Di Martino V. and Wirth L. Telework: A new way of working and living. International Labour Review, 1990, 129, No. 5, 529-554.

14. Nilles J. M. Telecommuting and urban sprawl: mitigator or inciter? Transportation, 1991, 18, 411-432.

15. Smart Valley Inc. Telecommuting-Two Years Later (A report on the state of telecommuting in the bay area). Smart Valley Inc., 1996.

16. Gray M. Teleworking. Computing \& Control Engineering Journal, 1996, 7, No. 1, 2-3.

17. Nilles J. M. Traffic reduction by telecommuting: a status review and selected bibliography. Transportation Research, 1988, 22A, No. 4, 301317.

18. Huws U. Teleworking: an Overview of the Research. Analytica Social and Economic Research Limited, 1996.

19. Office for National Statistics. Labour Force Survey. 1997.

20. Berry S. Teleworking today. Computing \& Control Engineering Journal, 1996, 7, No. 1, 4-10.

21. Korte W. B., Kordey N. and Robinson S. Telework in Europe: has it lived up to expectations? Penetration, potential and practice. I\&T Magazine, 1994, winter 1994-95 (16), 24-26.

22. Forsebäck L. 20 Seconds to Work: Home-based Telework-Swedish Experiences from a European Perspective, State of the Art 1995. Teldok Report $101 \mathrm{E}, 1995$.

23. Department of the Environment, Transport AND the Regions. National Road Traffic Forecasts (Great Britain). DETR, 1997.

24. Dodgson J., Sandbach J., Shurmer M., van Dijk T., Lane B. and McKinnon A. Motors or
Modems? A Report to the RAC prepared by the National Economic Research Associates, November 1997.

25. Institution of Civil Engineers. A Vision for Transport 2020. Thomas Telford, London, 1997.

26. Department of Transport. Transport Statistics Great Britain. HMSO, London, 1996.

27. Department of Transport. Transport Statistics Report: National Travel Survey 1994/96. HMSO, London, 1996.

28. Gillespie A., Richardson R. and Cornford J. Review of Telework in Britain: Implications for Public Policy. Centre for Urban and Regional Development Studies, University of Newcastle upon Tyne (prepared for the Parliamentary Office of Science and Technology), 1995.

29. Niles J. S. Beyond Telecommuting: A New Paradigm for the Effect of Telecommunications on Travel. Global Telematics, 1994.

30. Hopkins J. B., O'Donnell J. and Ritter G. T. Telecommuting: How much? How soon? Proceed ings of the IVHS Annual Meeting, 1994, Atlanta Georgia, 518-527.

31. Ritter G. and Thompson S. The rise of telecommuting and virtual transportation. Transportation Quarterly, 1994, 48, No. 3, summer, 235-248.

32. Salomon I. How much telecommuting should we count on? A forecast for Tel-Aviv in 2020. Transportation Research Record 1463, 1994, 26-34.

33. European Commission. EC Status Report on European Telework. Directorate XIII-B, 1997.

34. Department of the Environment, Transport And the Regions. A New Deal for Transport: Better for Everyone. Transport White Paper, TSO, 1998.

Please email, fax or post your discussion contributions to the Publisher: email: ttjournals@ice.org.uk; Fax: 0171538 9620; or post to Terri Harding, Journals Department, Thomas Telford Limited, Thomas Telford House, 1 Heron Quay, London E14 4JD 